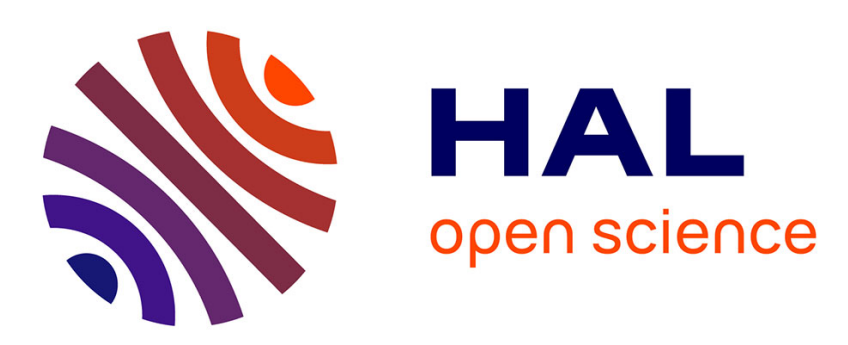

\title{
Association Between Planned Cesarean Delivery and Neonatal Mortality and Morbidity in Twin Pregnancies
}

Thomas Schmitz, Caroline Prunet, Elie Azria, Caroline Bohec, André Bongain, Pierre Chabanier, Claude D'ercole, Philippe Deruelle, Renaud de Tayrac, Michel Dreyfus, et al.

\section{To cite this version:}

Thomas Schmitz, Caroline Prunet, Elie Azria, Caroline Bohec, André Bongain, et al.. Association Between Planned Cesarean Delivery and Neonatal Mortality and Morbidity in Twin Pregnancies. Obstetrics and Gynecology, 2017, 129 (6), pp.986-995. 10.1097/AOG.0000000000002048 . hal-01653189

\section{HAL Id: hal-01653189 \\ https://hal.science/hal-01653189}

Submitted on 30 Sep 2019

HAL is a multi-disciplinary open access archive for the deposit and dissemination of scientific research documents, whether they are published or not. The documents may come from teaching and research institutions in France or abroad, or from public or private research centers.
L'archive ouverte pluridisciplinaire HAL, est destinée au dépôt et à la diffusion de documents scientifiques de niveau recherche, publiés ou non, émanant des établissements d'enseignement et de recherche français ou étrangers, des laboratoires publics ou privés. 


\title{
Association Between Planned Cesarean Delivery and Neonatal Mortality and Morbidity in Twin Pregnancies
}

\author{
Thomas Schmitz, MD, PhD, Caroline Prunet, MSc, Elie Azria, MD, PhD, Caroline Bohec, MD, \\ André Bongain, MD, Pierre Chabanier, MD, Claude D'Ercole, MD, Philippe Deruelle, MD, PhD, \\ Renaud De Tayrac, MD, PhD, Michel Dreyfus, MD, Corinne Dupont, PhD, Jean Gondry, MD, \\ Olivier Graesslin, MD, PhD, Gilles Kayem, MD, PhD, Bruno Langer, MD, PhD, Loïc Marpeau, MD, \\ Olivier Morel, MD, PhD, Olivier Parant, MD, PhD, Franck Perrotin, MD, PhD, Fabrice Pierre, MD, \\ Patrice Poulain, MD, Didier Riethmuller, MD, Patrick Rozenberg, MD, René-Charles Rudigoz, MD, \\ Paul Sagot, MD, Marie-Victoire Sénat, MD, PhD, Loïc Sentilhes, MD, PhD, Christophe Vayssière, MD, PhD, \\ Françoise Venditelli, $M D$, PhD, Eric Verspyck, MD, PhD, Norbert Winer, MD, PhD, Laurence Lecomte-Raclet, PhD, \\ Pierre-Yves Ancel, MD, PhD, and Francois Goffinet, MD, PhD, for the JUmeaux MODe d'Accouchement \\ (JUMODA) Study Group and the Groupe de Recherche en Obstétrique et Gynécologie (GROG)
}

OBJECTIVE: To evaluate the association between the planned mode of delivery and neonatal mortality and morbidity in an unselected population of women with twin pregnancies.

METHODS: The JUmeaux MODe d'Accouchement (JUMODA) study was a national prospective population-
From the Assistance Publique-Hôpitaux de Paris, Hôpital Robert Debré, Service de Gynécologie Obstétrique, Université Paris Diderot, INSERM, U1153, Epidemiology and Biostatistics Sorbonne Paris Cité Research Center, Obstetrical, Perinatal and Pediatric Epidemiology Team, Maternité Notre Dame de Bon Secours, Groupe Hospitalier Saint-Joseph, and Université René Descartes, Paris, Hôpital François Mitterrand, Service de Gynécologie Obstétrique, Pau, CHU de Nice, Service de Gynécologie Obstétrique, and Université de Nice Sophia Antepolis, Nice, CHU de Bordeaux, Service de Gynécologie Obstétrique, Bordeaux, Assistance Publique-Hôpitaux de Marseille, Hôpital Nord, Service de Gynécologie Obstétrique, and Université d'Aix-Marseille, Marseille, CHRU de Lille, Maternité Jeanne de Flandre, and Université de Lille 2, Lille, CHU de Nîmes, Service de Gynécologie Obstétrique, Nìmes, Université de Montpellier 1, Montpellier, CHU de Caen, Service de Gynécologie Obstétrique, and Université de Caen, Caen, Réseau Aurore, Lyon, CHU d'Amiens, Service de Gynécologie Obstétrique, and Université d'Amiens, Amiens, CHU de Reims, Service de Gynécologie Obstétrique, and Université de Reims, Reims, France; Assistance Publique-Hôpitaux de Paris, Hôpital Louis Mourier, Service de Gynécologie Obstétrique, and Université Pierre et Marie Curie, Paris, CHU de Strasbourg, Service de Gynécologie Obstétrique, and Université de Strasbourg, Strasbourg, CHU de Rouen, Service de Gynécologie Obstétrique, and Université de Rouen, Rouen, Maternité Régionale de Nancy, and Université de Nancy, Nancy, CHU de Toulouse, Service de Gynécologie Obstétrique, and Université Toulouse III Paul Sabatier, Toulouse, CHRU de Tours, Service de Gynécologie Obstétrique, and Université de François Rabelais, Tours, CHU de Potiers, Service de Gynécologie Obstétrique, and Université de Poitiers, Poitiers, CHU de Rennes, Service de Gynécologie Obstétrique, and Université de Rennes 1, Rennes, CHU de Besançon, Service de Gynécologie Obstétrique, and Université de Besançon, Besançon, Centre Hospitalier Intercommunal de Poissy, Service de Gynécologie Obstétrique, Poissy, Université de Versailles Saint-Quentin-en-Yvelines, Versailles, Hospices Civiles de Lyon, Hôpital de la Croix Rousse, Service de Gynécologie Obstétrique, and Université de Lyon 1, Lyon, CHU de Dijon, Service de Gynécologie Obstétrique, and Université de Bourgogne, Dijon, Assistance Publique-Hôpitaux de Paris, Hồpital Bicêtre, Service de Gynécologie Obstétrique, and Université Paris Sud, Le Kremlin Bicêtre, CHU d'Angers, Service de Gynécologie Obstétrique, and Université d'Angers, Angers, CHU de Clermont-Ferrand, Service de Gynécologie Obstétrique, and Université d'Auvergne, Clermont-Ferrand, CHU de Nantes, Service de Gynécologie Obstétrique, and Université de Nantes, Nantes, and URC-CIC P1419, Assistance Publique-Hôpitaux de Paris, Hôpital Cochin Hôtel Dieu, Assistance Publique-Hôpitaux de Paris, Maternité Port-Royal, and and DHU risques et grossesse, Paris, France.

Supported by a grant from the French Ministry of Health (Programme Hospitalier de Recherche Clinique, AOM2012).

Presented at the 37th Annual Meeting of the Society for Maternal-Fetal Medicine, January 23-28, 2017, Las Vegas, Nevada.

For a list of participating centers and collaborators related to this study, see Appendix 1, available online at http://links.lww.com/AOG/A949.

Each author has indicated that he or she has met the journal's requirements for authorship.

Corresponding author: Thomas Schmitz, MD, PhD, Service de Gynécologie Obstétrique, Hôpital Robert Debré, 48 Boulevard Sérurier, 75019 Paris, France; email: thomas.schmitz@aphp.fr.

\section{Financial Disclosure}

Dr. Langer carried out consultancy work for Procter \& Gamble France. Dr. Sentilhes carried out consultancy work and has been a lecturer for Ferring Laboratories. The other authors did not report any potential conflicts of interest. 
based cohort study. All women with twin pregnancies and their neonates born at or after 32 weeks of gestation with a cephalic first twin were recruited in $\mathbf{1 7 6}$ maternity units in France from February 2014 to March 2015. The primary outcome was a composite of intrapartum mortality and neonatal mortality and morbidity. Comparisons were performed according to the planned mode of delivery, planned cesarean or planned vaginal delivery. The primary analysis to control for potential indication bias used propensity score matching. Subgroup analyses were conducted, one according to gestational age at delivery and one after exclusion of high-risk pregnancies.

RESULTS: Among 5,915 women enrolled in the study, $1,454(24.6 \%)$ had planned cesarean and 4,461 (75.4\%) planned vaginal deliveries, of whom 3,583 (80.3\%) delivered both twins vaginally. In the overall population, composite neonatal mortality and morbidity was increased in the planned cesarean compared with the planned vaginal delivery group (5.2\% compared with $2.2 \%$; odds ratio [OR] 2.38, 95\% confidence interval [CI] 1.86-3.05). After matching, neonates born after planned cesarean compared with planned vaginal delivery had higher composite neonatal mortality and morbidity rates $(5.3 \%$ compared with $3.0 \%$; OR 1.85, 95\% confidence interval 1.29-2.67). Differences in composite mortality and morbidity rates applied to neonates born before but not after 37 weeks of gestation. Multivariate and subgroup analyses after exclusion of highrisk pregnancies found similar trends.

CONCLUSION: Planned vaginal delivery for twin pregnancies with a cephalic first twin at or after 32 weeks of gestation was associated with low composite neonatal mortality and morbidity. Moreover, planned cesarean compared with planned vaginal delivery before 37 weeks of gestation might be associated with increased composite neonatal mortality and morbidity.

(Obstet Gynecol 2017;129:986-95)

DOI: 10.1097/AOG.0000000000002048

T wins account for $3-3.5 \%$ of all births, ${ }^{1,2}$ but their optimal mode of delivery remains controversial. Hospital-based retrospective studies did not provide evidence of increased adverse neonatal outcomes for both twins after vaginal birth in comparison with cesarean delivery. ${ }^{3-5}$ Conversely, large populationbased retrospective cohorts have shown an association between vaginal delivery and increased neonatal mortality and morbidity, ${ }^{6-9}$ mainly for the second twin. ${ }^{7,8}$ As a result of these conflicting data, the cesarean delivery rate for twin pregnancy has increased up to $75 \%$ in the United States in $2008^{10}$ and to $45 \%$ in France in $2010 .{ }^{1}$ Recently, a large international randomized trial showed that planned cesarean delivery did not significantly decrease or increase perinatal mortality or morbidity compared with planned vagi- nal delivery in twin pregnancies with a cephalic first twin between 32 and 39 weeks of gestation. ${ }^{11}$ This result led the American College of Obstetricians and Gynecologists and the Society for Maternal-Fetal Medicine to encourage vaginal delivery of twins. ${ }^{12}$ Nonetheless, other strong and consistent evidence supporting these recommendations is lacking, especially in unselected populations for which the results of the randomized trial might not be generalizable.

Hospital-based retrospective studies are underpowered, large database population cohort studies are flawed by indication biases and data of questionable validity, ${ }^{13}$ do not allow comparison according to the planned mode of delivery and collection of potential confounding variables, and randomized trials generate a selection of the study sample compromising their external validity and accuracy. ${ }^{14,15}$ Therefore, we performed a national, observational, prospective, population-based cohort study-another way to evaluate complex phenomena. ${ }^{14,15}$ The JUmeaux MODe d'Accouchement (JUMODA) study, specially designed to answer this question with sufficient statistical power and high-quality data, provided a unique opportunity to evaluate the neonatal risks associated with planned mode of delivery in an unselected population of women with twin pregnancies.

\section{MATERIALS AND METHODS}

The JUMODA study was a national, observational, prospective, population-based cohort study conducted from February 10, 2014, through March 1, 2015, in France, where guidelines recommend active management of second twin delivery with immediate total breech extraction in case of breech presentation, internal version and total breech extraction in case of transverse or cephalic presentation above a 0 station and artificial membrane rupture and pushing efforts in case of cephalic presentation at or below a 0 station. ${ }^{16}$ Maternity units delivering more than 1,500 women annually were invited to participate, regardless of their academic, public, or private status or level of care; financial considerations prevented participation of smaller units. Women who gave birth at or after 22 weeks of gestation were eligible. Enrollment took place prospectively immediately after delivery. This primary analysis of the JUMODA cohort focuses on the population of women with both a twin pregnancy and first twin in a cephalic position and who gave birth at or after 32 weeks of gestation. A secondary analysis on the population of women who gave birth before 32 weeks of gestation is not part of this article and will be undertaken later. 
Recruitment and data collection occurred only after women had received information and provided oral informed consent to participate. The National Data Protection Authority (DR-2013-528), the consultative committee on the treatment of information on personal health data for research purposes (13298), and the committee for the protection of people participating in biomedical research (PP-13-014) approved this study.

Immediately after delivery, obstetricians used women's medical files to complete a detailed webbased questionnaire about planned mode of delivery, indications for planned cesarean delivery or induction of labor, and details about management of delivery and classified them as planned cesarean or planned vaginal deliveries.

Research nurses collected data about maternal characteristics, medical history, pregnancy complications, and neonatal health. The primary outcome was a composite of intrapartum mortality and neonatal mortality and morbidity very similar to the primary outcome of the Twin Birth Study. ${ }^{11}$ Neonatal mortality was assessed during the first 28 days of life. Neonatal morbidity was defined as one or more of the following: 5-minute Apgar score less than 4 ; birth trauma (humerus, femur, or skull fracture, spinal cord injury, or brachial plexus palsy); injury of the phrenic or facial nerve present at 72 hours of age or at hospital discharge; subdural or intracerebral hemorrhage (confirmed by ultrasonography, computed tomography, or magnetic resonance imaging); encephalopathy according to the Sarnat classification; seizures on at least two occasions before 72 hours of age; endotracheal ventilation within 72 hours after birth for at least 24 hours; proven neonatal sepsis during neonatal hospitalization, defined by a positive blood culture or cerebrospinal fluid culture; bronchopulmonary dysplasia, defined as the need for supplemental oxygen at a postnatal gestational age of 36 weeks; intraventricular hemorrhage or cystic periventricular leukomalacia confirmed by ultrasonography; and stage II and III necrotizing enterocolitis according to Bell staging. This primary outcome was treated as a binary variable.

In the primary analysis, we used a propensity score matching approach to limit indication bias resulting from the different risk levels in each planned delivery group and to control for confounding factors that might influence both the planned mode of delivery and the primary outcome. ${ }^{17}$ The propensity score was defined as the probability that a cesarean delivery would have been planned for the patient.
Details on the propensity score construction are provided in Appendix 2, available online at http://links. lww.com/AOG/A949. The unit of analysis was the neonate.

Two additional secondary analyses were performed in the overall cohort. First, we used multivariable logistic regression models to assess the relationship between the planned mode of delivery and the primary outcome after adjustment for factors associated with the primary outcome with a $P$ value $<.2$ in the univariate analysis. Second, we used adjustment on gestational age at delivery and inverse probability-of-treatment weighting ${ }^{17}$ on the basis of estimated propensity scores to obtain a synthetic population in which treatment assignment is independent of measured baseline covariates. We estimated the association between the planned mode of delivery and outcomes, obtaining adjusted odds ratios (ORs) and $95 \%$ confidence intervals (CIs).

Next, we performed two subgroup analyses. First, we repeated the previous analyses according to gestational age at delivery, that is, for women delivering between $320 / 7$ and $346 / 7$ weeks of gestation, between $350 / 7$ and 36 6/7 weeks of gestation, and at or after 37 0/7 weeks of gestation. Second, we ran the analyses described previously after exclusion of women at high risk for adverse neonatal outcome, that is, women with pregnancy complications (one or more of the following: preeclampsia, placental abruption, suspected fetal growth restriction for either twin, insulin-treated diabetes, placenta previa, malformation of either twin, twin-twin transfusion syndrome), and those with intrauterine fetal deaths, fetal reduction after 13 weeks of gestation, or monoamniotic twin pregnancies. These exclusion criteria, mimicking those of the Twin Birth Study, ${ }^{11}$ created a so-called "low-risk" population.

In all analyses, generalized estimating equations were applied to take the correlation between the first and second twin from the same pregnancy into account. Finally, we tested the interaction between the planned mode of delivery and birth order after propensity score matching. All tests were two-sided. $P$ values $<.05$ were considered significant. All analyses were performed with SAS 9.3.

\section{RESULTS}

During the study period, 8,823 women in the 176 participating maternity units gave birth to twins after 22 weeks of gestation, 5,915 of them at or after $320 / 7$ weeks of gestation with a cephalic first twin. These 5,915 women represented $95.1 \%$ of the women $(\mathrm{n}=6,220)$ having delivered twins with the inclusion 


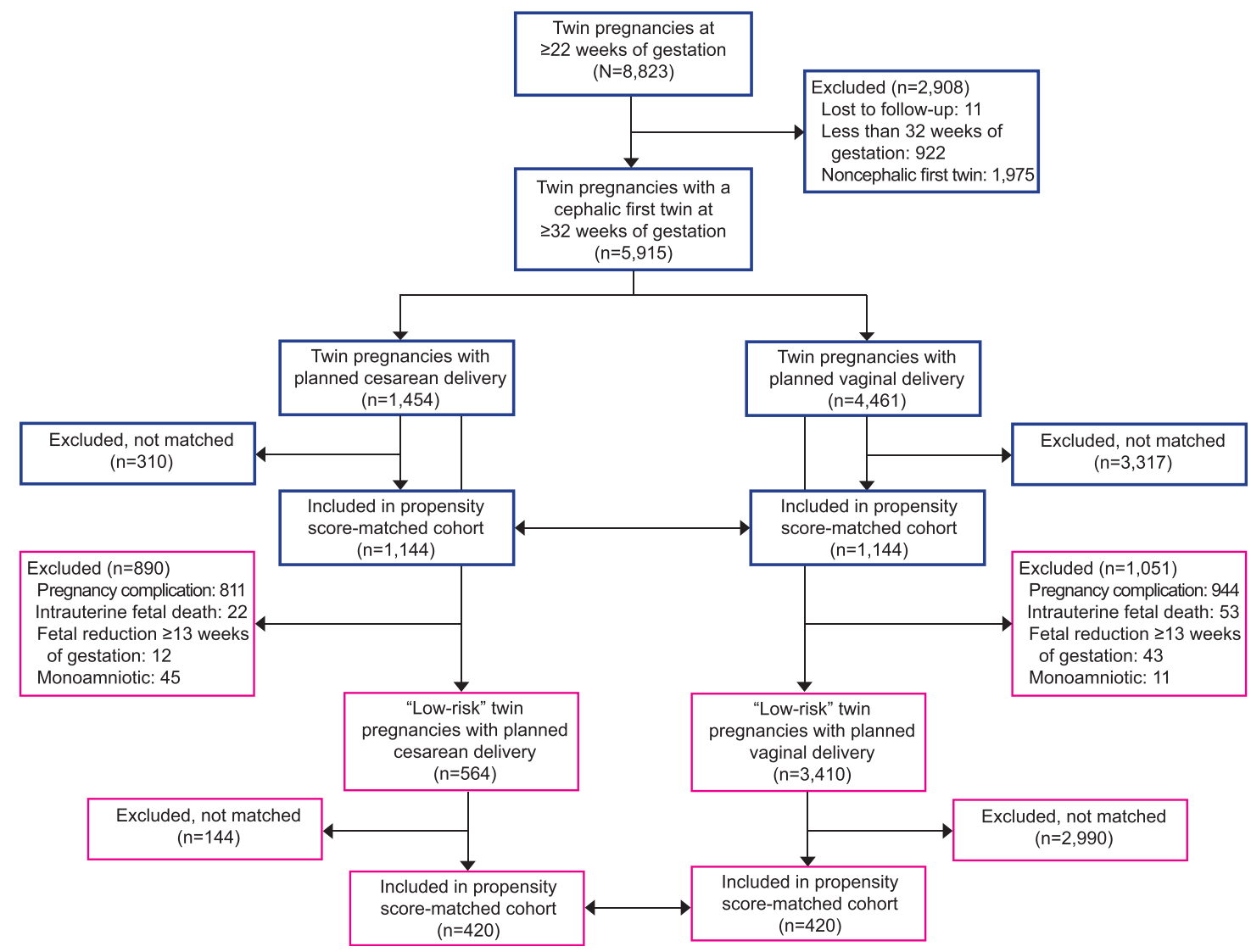

Fig. 1. Flow chart for the JUmeaux Mode d'Accouchement (JUMODA) study. Navy boxes indicate principal analysis in the overall cohort. Pink boxes indicate subgroup analysis of the "low-risk" population.

Schmitz. Planned Mode of Delivery and Neonatal Morbidity in Twins. Obstet Gynecol 2017.

criteria in the participating centers during the study period because inclusions of 305 women were missed. Among them, 1,454 (24.6\%) had planned cesarean and 4,461 (75.4\%) planned vaginal deliveries (Fig. 1). Of those with planned cesarean deliveries, $25(1.7 \%)$ delivered both twins vaginally and three $(0.2 \%)$ had

Table 1. Characteristics of Women's Labor and Delivery

\begin{tabular}{|c|c|c|c|}
\hline Characteristic & Planned Cesarean Delivery (n5 1,454) & Planned Vaginal Delivery (n5 4,461) & $P$ \\
\hline Spontaneous labor & $280(19.3)$ & $2,244(50.3)$ & $<.001$ \\
\hline Mode of delivery & & & $<.001$ \\
\hline Cesarean for both & $1,426(98.1)$ & $754(16.9)$ & \\
\hline Vaginal and cesarean & $3(0.2)$ & $119(2.7)$ & \\
\hline Vaginal for both & $25(1.7)$ & $3,583(80.3)$ & \\
\hline Timing of cesarean delivery & & & $<.001$ \\
\hline No cesarean delivery & $25(1.7)$ & $3,583(80.3)$ & \\
\hline Before labor & $1,169(80.7)$ & $1(0.0)$ & \\
\hline During labor & $255(17.6)$ & $872(19.7)$ & \\
\hline Analgesia & & & $<.001$ \\
\hline None & $6(0.4)$ & $144(3.2)$ & \\
\hline Intravenous & $0(0.0)$ & $13(0.3)$ & \\
\hline Locoregional & $1,371(94.3)$ & $4,260(95.5)$ & \\
\hline General & $77(5.3)$ & $43(1.0)$ & \\
\hline Active 2 nd twin delivery & $24(1.7)$ & $3,106(69.9)$ & $<.001$ \\
\hline Interval between births (min) & $1.0(1.0-2.0)$ & $5.0(3.0-9.0)$ & $<.001$ \\
\hline
\end{tabular}

Data are $\mathrm{n}(\%)$ or median (quartile 1-quartile 3) unless otherwise specified. 


\begin{tabular}{|c|c|c|c|c|c|c|}
\hline \multirow[b]{2}{*}{ Characteristic } & \multicolumn{3}{|c|}{ Overall Cohort } & \multicolumn{3}{|c|}{ Matched Cohort } \\
\hline & $\begin{array}{l}\text { Planned } \\
\text { Cesarean } \\
\text { Delivery } \\
(n=1,454)\end{array}$ & $\begin{array}{l}\text { Planned } \\
\text { Vaginal } \\
\text { Delivery } \\
(n=4,461)\end{array}$ & $\begin{array}{l}\text { Standardized } \\
\text { Difference }\end{array}$ & $\begin{array}{l}\text { Planned } \\
\text { Cesarean } \\
\text { Delivery } \\
(n=1,144)\end{array}$ & $\begin{array}{l}\text { Planned } \\
\text { Vaginal } \\
\text { Delivery } \\
(n=1,144)\end{array}$ & $\begin{array}{c}\text { Standardized } \\
\text { Difference }\end{array}$ \\
\hline \multicolumn{7}{|l|}{ Maternal } \\
\hline Age (y) & $32.8 \pm 5.8$ & $31.4 \pm 5.1$ & 26.4 & $32.4 \pm 5.8$ & $32.1 \pm 5.6$ & 5.1 \\
\hline Nulliparous & $662(45.6)$ & $2,092(47.0)$ & 2.8 & $598(52.3)$ & $662(57.8)$ & 11.1 \\
\hline \multicolumn{7}{|l|}{ BMI $\left(\mathrm{kg} / \mathrm{m}^{2}\right)$ before pregnancy } \\
\hline Less than 18.5 & $89(6.4)$ & $294(6.9)$ & 1.7 & $76(6.7)$ & $83(7.2)$ & 2.1 \\
\hline $18.5-24.9$ & $774(56.0)$ & $2,740(63.9)$ & 16.1 & $665(58.1)$ & $666(58.2)$ & 0.2 \\
\hline $25-29.9$ & $312(22.6)$ & $839(19.6)$ & 7.4 & $251(21.9)$ & $246(21.5)$ & 0.9 \\
\hline 30 or greater & $207(15.0)$ & $418(9.7)$ & 16.0 & $152(13.3)$ & $149(13.0)$ & 0.7 \\
\hline Smoker & $223(15.9)$ & $612(14.2)$ & 4.7 & $175(15.3)$ & $185(16.2)$ & 2.5 \\
\hline Previous cesarean delivery & $471(32.4)$ & $151(3.4)$ & 81.8 & $231(20.2)$ & $150(13.1)$ & 19.0 \\
\hline \multicolumn{7}{|l|}{ Pregnancy and delivery } \\
\hline IVF, ICSI & $379(26.3)$ & $959(21.6)$ & 10.9 & $305(26.7)$ & 319 (27.9) & 2.7 \\
\hline 1st-trimester ultrasonography & $1,303(96.1)$ & 4,061 (95.8) & 1.4 & $1,084(94.7)$ & $1,088(95.1)$ & 1.6 \\
\hline $\begin{array}{c}\text { Fetal reduction at } 13 \text { wk of } \\
\text { gestation or more }\end{array}$ & $12(0.8)$ & $43(1.0)$ & 1.5 & $10(0.8)$ & $10(0.8)$ & 0.0 \\
\hline \multicolumn{7}{|l|}{ Chorionicity } \\
\hline Dichorionic & $1,074(74.2)$ & $3,546(79.8)$ & 13.3 & $856(74.8)$ & $880(76.9)$ & 4.9 \\
\hline $\begin{array}{l}\text { Monochorionic and } \\
\text { diamniotic }\end{array}$ & $329(22.7)$ & $884(19.9)$ & 6.9 & $269(23.6)$ & $253(22.1)$ & 3.4 \\
\hline $\begin{array}{l}\text { Monochorionic and } \\
\text { monoamniotic }\end{array}$ & $45(3.1)$ & $11(0.3)$ & 22.4 & $19(1.7)$ & $11(1.0)$ & 6.1 \\
\hline Unknown & $0(0.0)$ & $5(0.1)$ & 4.7 & $0(0.0)$ & $0(0.0)$ & - \\
\hline Complications & $708(48.7)$ & $1,055(23.7)$ & 54.4 & $555(48.5)$ & $562(49.1)$ & 1.3 \\
\hline Hypertension & $115(7.9)$ & $203(4.6)$ & & $87(7.6)$ & $119(10.4)$ & \\
\hline Preeclampsia & $227(15.6)$ & $336(7.6)$ & & $174(15.2)$ & $194(17.0)$ & \\
\hline Placental abruption & $7(0.5)$ & $3(0.1)$ & & $6(0.5)$ & $2(0.1)$ & \\
\hline $\begin{array}{l}\text { Suspected FGR for either } \\
\text { twin }\end{array}$ & $402(27.7)$ & $510(11.5)$ & & $327(28.6)$ & $263(23.0)$ & \\
\hline Insulin-treated diabetes & $75(5.2)$ & $126(2.8)$ & & $42(3.7)$ & $67(5.9)$ & \\
\hline Placenta previa & $31(2.1)$ & $7(0.2)$ & & $26(2.3)$ & $4(0.3)$ & \\
\hline $\begin{array}{l}\text { Malformation for either } \\
\text { twin }\end{array}$ & $38(2.6)$ & $97(2.2)$ & & $29(2.5)$ & $43(3.7)$ & \\
\hline $\begin{array}{l}\text { Twin-twin transfusion } \\
\text { syndrome }\end{array}$ & 57 (3.9) & $61(1.4)$ & & $45(4.0)$ & $32(2.8)$ & \\
\hline $\begin{array}{c}\text { Prelabor rupture of } \\
\text { membranes }\end{array}$ & $107(7.4)$ & $358(8.1)$ & 2.6 & $88(7.7)$ & $86(7.5)$ & 0.6 \\
\hline Preterm labor & $375(25.8)$ & $1,486(33.4)$ & 16.6 & $327(28.6)$ & $338(29.5)$ & 2.0 \\
\hline $\begin{array}{l}\text { Hospitalization during } \\
\text { pregnancy }\end{array}$ & $692(47.6)$ & $2,041(45.8)$ & 3.6 & $574(50.2)$ & $572(50.4)$ & 0.5 \\
\hline Antenatal corticosteroids & $689(47.6)$ & $1,787(40.2)$ & 14.9 & $544(47.5)$ & $556(48.6)$ & 2.2 \\
\hline \multicolumn{7}{|l|}{$\begin{array}{c}\text { 2nd twin presentation at } \\
\text { delivery }\end{array}$} \\
\hline Cephalic & $703(48.4)$ & $2,755(61.8)$ & 27.2 & $574(50.1)$ & $572(50.0)$ & 0.3 \\
\hline Breech & $544(37.4)$ & $1,131(25.4)$ & 26.2 & $408(35.7)$ & $407(35.6)$ & 0.1 \\
\hline Transverse & $207(14.2)$ & $575(12.9)$ & 3.9 & $163(14.2)$ & $165(14.4)$ & 0.6 \\
\hline \multicolumn{7}{|l|}{ Neonatal } \\
\hline Gestational age at birth (wk) & $35.6 \pm 2.0$ & $36.4 \pm 1.8$ & 40.2 & $35.7 \pm 1.9$ & $35.7 \pm 1.9$ & 0.0 \\
\hline $320 / 7-346 / 7$ & $450(31.0)$ & $754(16.9)$ & 33.4 & $336(29.4)$ & $336(29.4)$ & 0.0 \\
\hline 35 0/7-36 6/7 & $434(29.8)$ & $1,276(28.6)$ & 2.7 & $354(30.9)$ & $354(30.9)$ & 0.0 \\
\hline $370 / 7$ or greater & $570(39.2)$ & $2,431(54.5)$ & 31.0 & $454(39.7)$ & $454(39.7)$ & 0.0 \\
\hline
\end{tabular}


Table 2. Selected Maternal, Pregnancy, Delivery, and Neonatal Characteristics in the Overall and Matched Cohorts (continued)

\begin{tabular}{|c|c|c|c|c|c|c|}
\hline \multirow[b]{2}{*}{ Characteristic } & \multicolumn{3}{|c|}{ Overall Cohort } & \multicolumn{3}{|c|}{ Matched Cohort } \\
\hline & $\begin{array}{l}\text { Planned } \\
\text { Cesarean } \\
\text { Delivery } \\
(n=1,454)\end{array}$ & $\begin{array}{c}\text { Planned } \\
\text { Vaginal } \\
\text { Delivery } \\
(\mathrm{n}=4,461)\end{array}$ & $\begin{array}{c}\text { Standardized } \\
\text { Difference }\end{array}$ & $\begin{array}{c}\text { Planned } \\
\text { Cesarean } \\
\text { Delivery } \\
(n=1,144)\end{array}$ & $\begin{array}{c}\text { Planned } \\
\text { Vaginal } \\
\text { Delivery } \\
(\mathrm{n}=1,144)\end{array}$ & $\begin{array}{c}\text { Standardized } \\
\text { Difference }\end{array}$ \\
\hline \multicolumn{7}{|c|}{$\begin{array}{l}\text { Birth weight less than the } \\
\text { 10th centile }\end{array}$} \\
\hline 1st twin & $527(36.3)$ & $1,549(34.8)$ & 3.2 & $439(38.4)$ & 441 (38.6) & 0.4 \\
\hline 2nd twin & $656(45.2)$ & $1,923(43.3)$ & 4.0 & $534(46.7)$ & $542(47.4)$ & 1.4 \\
\hline \multicolumn{7}{|l|}{ Male sex } \\
\hline 1st twin & $718(49.4)$ & $2,310(51.8)$ & 4.8 & $572(50.0)$ & $578(50.5)$ & 1.0 \\
\hline 2nd twin & 689 (47.4) & $2,221(49.9)$ & 4.9 & $558(48.8)$ & $562(49.1)$ & 0.6 \\
\hline
\end{tabular}

BMI, body mass index; IVF, in vitro fertilization; ICSI, intracytoplasmic sperm injection; FGR, fetal growth restriction.

Data are mean \pm standard deviation, $\%$, or $\mathrm{n}(\%)$ unless otherwise specified.

cesarean deliveries for the second twin after vaginal delivery of the first twin (Table 1). Among women with planned vaginal deliveries, $754(16.9 \%)$ delivered both twins by cesarean and $119(2.7 \%)$ had a cesarean delivery for the second twin after vaginal birth of the first twin (Table 1). As shown in Table 2, in comparison with women of the planned vaginal delivery group, women of the planned cesarean delivery group were older, more often obese, had more previous cesarean deliveries, monochorionic twin pregnancies, pregnancy complications, and the second twin in breech presentation. They delivered at earlier gestational age of smaller neonates than in the planned vaginal delivery group. To control for indication bias and bypass these differences, we performed a propensity-matched analysis.

Propensity scores were calculated for the 5,915 women. Distributions of the propensity scores before and after matching are summarized in Appendices 3 and 4, available online at http://links.lww.com/AOG/ A949. The area under the receiver operating curve was 0.83 (95\% CI 0.82-0.85). Of these 5,915 women, 2,288 could be matched: 1,144 in each group (planned cesarean and planned vaginal delivery). The matched groups were found to be well balanced (standardized difference less than 10\%) except for previous cesarean delivery (standardized difference 19.3\%; Table 2; Appendix 5 [available online at http://links.lww.com/AOG/A949]). After adjustment for previous cesarean delivery, the matched neonates born after planned cesarean, compared with planned vaginal, delivery had a higher rate of composite neonatal mortality and morbidity $(5.3 \%$ compared with 3.0\%; OR 1.85, 95\% CI 1.29-2.67; Fig. 2; Table 3). Respiratory morbidity and sepsis were the two most frequent contributors to the increased composite neo- natal mortality and morbidity rate in the planned cesarean delivery group (Table 3).

The results of the secondary analyses were consistent with those of the primary analysis based on propensity score matching. In the overall cohort, the difference for the primary outcome was more pronounced $(5.2 \%$ compared with $2.2 \%$; OR $2.38,95 \%$ CI 1.86-3.05). Causes of neonatal death in the planned cesarean delivery group $(\mathrm{n}=16)$ were multiple malformation or genetic syndromes $(n=8)$, severe fetal growth restriction $(\mathrm{n}=2)$, maternal sudden cardiac death $(\mathrm{n}=1)$, and hypoxia $(\mathrm{n}=5)$. In the planned vaginal delivery group, causes of neonatal death $(n=11)$ were multiple malformation or genetic syndromes $(\mathrm{n}=7)$, septicemia $(\mathrm{n}=1)$, and complications of vaginal delivery $(\mathrm{n}=3)$. Use of multivariable logistic regression (adjusted OR 1.56, 95\% CI 1.19-2.04) and inverse probability of treatment weighting (adjusted OR 1.78, 95\% CI 1.52-2.10) provided similar results (Fig. 2).

Subgroup analyses according to gestational age at delivery showed that the higher risk associated with planned cesarean deliveries existed only among women giving birth between $320 / 7$ and $346 / 7$ weeks of gestation and between $350 / 7$ and 36 6/7 weeks of gestation (Fig. 2). At or after 37 0/7 weeks of gestation, composite mortality and morbidity was similar in each group (Fig. 2).

After exclusion of the high-risk pregnancies, 564 $(14.2 \%)$ women had planned cesarean deliveries and 3,410 (85.8\%) planned vaginal deliveries (Fig. 1). Distributions of maternal, pregnancy, delivery, and neonatal characteristics are provided in Appendix 6, available online at http://links.lww.com/AOG/ A949. The propensity-matched and secondary analyses in the low-risk population demonstrated no significant association between planned cesarean delivery 


\begin{tabular}{|c|c|c|c|c|c|}
\hline & lanned cesarean & Planned vaginal & & & \\
\hline Analysis Method & $\mathrm{n} / \mathrm{N}(\%)$ & $\mathrm{n} / \mathrm{N}(\%)$ & OR $(95 \% \mathrm{Cl})$ & & \\
\hline \multicolumn{6}{|l|}{ Overall population } \\
\hline \multicolumn{5}{|l|}{$\geq 32$ wk 0 days } & $=$ \\
\hline Adjusted* & $150 / 2908(5.2)$ & $199 / 8922(2.2)$ & $1.56(1.19-2.04)$ & & 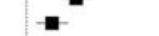 \\
\hline Propensity score, matching & $120 / 2288(5.3)$ & $69 / 2288(3.0)$ & $1.85(1.29-2.67)$ & & - \\
\hline \multicolumn{6}{|c|}{32 wk 0 days to 34 wk 6 days } \\
\hline Crude & $104 / 900(11.6)$ & $110 / 1508(7.3)$ & $1.66(1.20-2.29)$ & & - \\
\hline Adjusted* & $104 / 900(11.6)$ & $110 / 1508(7.3)$ & $1.64(1.13-2.39)$ & & $\bar{z}$ \\
\hline Propensity score, matching & $76 / 644$ (11.7) & $47 / 644(7.3)$ & $1.72(1.09-2.70)$ & & $\vec{a}$ \\
\hline \multicolumn{6}{|l|}{35 wk 0 days to 36 wk 6 days } \\
\hline Crude & $35 / 868(4.0)$ & $45 / 2552(1.8)$ & $2.34(1.42-3.85)$ & & - \\
\hline Adjusted* & $35 / 868(4.0)$ & $45 / 2552(1.8)$ & $2.04(1.22-3.41)$ & & $=$ \\
\hline Propensity score, matching & $31 / 700(4.5)$ & $13 / 700(1.9)$ & $2.52(1.05-6.04)$ & & $=$ \\
\hline \multicolumn{6}{|l|}{$\geq 37$ wk 0 days } \\
\hline Adjusted* & $11 / 1140(1.0)$ & $44 / 4862(0.9)$ & $1.19(0.58-2.44)$ & & 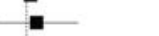 \\
\hline Propensity score, matching & $5 / 828(0.6)$ & $5 / 828(0.6)$ & $1.10(0.22-5.47)$ & & $\overline{-1}$ \\
\hline \multicolumn{6}{|l|}{ Low-risk population } \\
\hline \multicolumn{6}{|l|}{$\geq 32$ wk 0 days } \\
\hline Crude & $28 / 1128(2.5)$ & $133 / 6820(2.0)$ & $1.28(0.79-2.08)$ & & $=$ \\
\hline Adjustedt & $28 / 1128(2.5)$ & $133 / 6820(2.0)$ & $1.54(0.95-2.49)$ & & $=$ \\
\hline Propensity score, matching & $21 / 840(2.5)$ & $11 / 840(1.4)$ & $2.01(0.67-6.03)$ & & 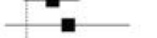 \\
\hline \multicolumn{6}{|l|}{32 wk 0 days to 34 wk 6 days } \\
\hline Crude & $20 / 116(17.2)$ & $77 / 1124(6.9)$ & $2.83(1.51-5.32)$ & & 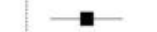 \\
\hline Adjustedt & $20 / 116(17.2)$ & $77 / 1124(6.9)$ & $2.57(1.31-5.05)$ & & $\overline{-1}$ \\
\hline Propensity score, matching & $20 / 113(17.3)$ & $10 / 113(8.8)$ & $2.61(0.87-7.83)$ & & $=$ \\
\hline \multicolumn{6}{|l|}{35 wk 0 days to 36 wk 6 days } \\
\hline Crude & $6 / 272(2.2)$ & $23 / 1730(1.3)$ & $1.67(0.60-4.65)$ & & $=$ \\
\hline Adjustedt & $6 / 272(2.2)$ & $23 / 1730(1.3)$ & $1.54(0.58-4.10)$ & & $=$ \\
\hline Propensity score, matching & $5 / 208(2.4)$ & $2 / 208(0.7)$ & $2.49(0.33-18.73)$ & & $\longrightarrow$ \\
\hline \multicolumn{6}{|l|}{$\geq 37$ wk 0 days } \\
\hline Crude & $2 / 740(0.3)$ & $33 / 3966(0.8)$ & $0.24(0.08-1.36)$ & 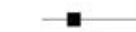 & - \\
\hline Adjustedt & $2 / 740(0.3)$ & $33 / 3966(0.8)$ & $0.37(0.08-1.67)$ & - & 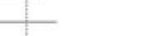 \\
\hline \multirow[t]{2}{*}{ Propensity score, matching } & $1 / 526(0.2)$ & $3 / 526(0.6)$ & $0.33(0.03-4.22)$ & $\longleftarrow$ & \\
\hline & & & & 0.060 .120 .250 .50 & $\begin{array}{lll}1.0 & 2.0 & 4.0608 .0 \\
\text { OR (OSXC1) }\end{array}$ \\
\hline
\end{tabular}

Fig. 2. Multivariable analysis for composite neonatal mortality and morbidity in the overall and lowrisk populations according to gestational age at delivery. *Adjusted for maternal age, parity, fetal reduction, in vitro fertilization, pregnancy complications, premature prelabor rupture of membranes, antenatal corticosteroids, hospitalization during pregnancy, gestational age at birth, birth weight less than the 10th percentile, number of twin pregnancies per center per year, and academic status. ${ }^{+}$Adjusted for maternal age, parity, in vitro fertilization, premature prelabor rupture of membranes, antenatal corticosteroids, hospitalization during pregnancy, gestational age at birth, birth weight less than the 10th percentile, number of twin pregnancies per center per year, and academic status. Composite neonatal morbidity and mortality was defined by one of the following events: peripartum death, neonatal death, Apgar score less than 4 at 5 minutes, neonatal trauma, encephalopathy, two or more seizures within 72 hours after birth, endotracheal tube inserted for greater than 24 hours within 72 hours after birth, proven neonatal sepsis, bronchopulmonary dysplasia, intraventricular hemorrhage, periventricular leukomalacia, and necrotizing enterocolitis. OR, odds ratio; $\mathrm{Cl}$, confidence interval.

Schmitz. Planned Mode of Delivery and Neonatal Morbidity in Twins. Obstet Gynecol 2017.

and the composite primary outcome (Fig. 2; Table 4). Analyses by gestational age in this subgroup showed that planned cesarean delivery was associated with higher composite neonatal mortality and morbidity only between $320 / 7$ and $346 / 7$ weeks of gestation (Fig. 2; Appendices 7-9, available online at http:// links.lww.com/AOG/A949).

Analyses performed without multiple imputation provided similar results in the overall and low-risk populations (data not shown). Finally, the interaction between planned mode of delivery and birth order was not significant $(P=.24)$.

\section{DISCUSSION}

Two main conclusions can be drawn from the results of the JUMODA study. First, high vaginal delivery rates with low neonatal mortality and morbidity are possible for twin pregnancies with a cephalic first twin at or after 32 weeks of gestation nationwide. The primary outcome rate in the planned vaginal delivery group in the overall population was similar to that reported in the international randomized Twin Birth Study, ${ }^{11}$ although the women of the JUMODA study, because of its population-based design, were at much higher perinatal risk.

Second, planned cesarean delivery was associated with higher neonatal morbidity than was planned vaginal delivery. This higher morbidity rate was observed only for twins born before 37 weeks of gestation in the overall cohort and before 35 weeks of gestation in the low-risk population. Although respiratory morbidity was the main 


\begin{tabular}{|c|c|c|c|c|c|c|}
\hline \multirow[b]{2}{*}{ Outcome } & \multicolumn{3}{|c|}{ Overall Cohort } & \multicolumn{3}{|c|}{ Matched Cohort } \\
\hline & $\begin{array}{l}\text { Planned } \\
\text { Cesarean } \\
\text { Delivery } \\
(n=2,908)\end{array}$ & $\begin{array}{l}\text { Planned } \\
\text { Vaginal } \\
\text { Delivery } \\
(\mathrm{n}=\mathbf{8}, 922)\end{array}$ & $\begin{array}{c}\text { OR } \\
(95 \% \mathrm{Cl})\end{array}$ & $\begin{array}{l}\text { Planned } \\
\text { Cesarean } \\
\text { Delivery } \\
(n=2,288)\end{array}$ & $\begin{array}{l}\text { Planned } \\
\text { Vaginal } \\
\text { Delivery } \\
(\mathrm{n}=2,288)\end{array}$ & $\begin{array}{c}\text { OR } \\
(95 \% \mathrm{Cl})\end{array}$ \\
\hline Composite primary outcome & $150(5.2)$ & $199(2.2)$ & $2.38(1.86-3.05)$ & $120(5.3)$ & $69(3.0)$ & $1.85(1.29-2.67)$ \\
\hline \multicolumn{7}{|l|}{ Death } \\
\hline Antepartum* & $23(0.8)$ & $55(0.6)$ & & $16(0.7)$ & $15(0.6)$ & \\
\hline Perpartum & 0 & 0 & & 0 & 0 & \\
\hline Neonatal & $16(0.6)$ & $11(0.1)$ & & $8(0.4)$ & $7(0.3)$ & \\
\hline Apgar score less than 4 at 5 min & $18(0.6)$ & $25(0.3)$ & & $16(0.7)$ & $11(0.5)$ & \\
\hline Neonatal trauma & $2(<0.1)$ & $11(0.1)$ & & $4(0.2)$ & $5(0.2)$ & \\
\hline Long bone fracture & 0 & $6(<0.1)$ & & 0 & $2(<0.1)$ & \\
\hline Brachial plexus palsy & 0 & $2(<0.1)$ & & 0 & $1(<0.1)$ & \\
\hline Skull fracture & $1(<0.1)$ & $3(<0.1)$ & & $2(<0.1)$ & $1(<0.1)$ & \\
\hline Spinal cord injury & $1(<0.1)$ & 0 & & $2(<0.1)$ & 0 & \\
\hline Encephalopathy & $7(0.2)$ & $13(0.2)$ & & $6(0.3)$ & $1(<0.1)$ & \\
\hline $\begin{array}{l}2 \text { or more seizures within } 72 \mathrm{~h} \\
\text { after birth }\end{array}$ & $1(<0.1)$ & $1(<0.1)$ & & 0 & 0 & \\
\hline $\begin{array}{l}\text { Endotracheal tube greater than } 24 \mathrm{~h} \\
\text { within } 72 \mathrm{~h} \text { after birth }\end{array}$ & $59(2.1)$ & $62(0.7)$ & & $37(1.6)$ & $17(0.7)$ & \\
\hline Proven neonatal sepsis & $55(1.9)$ & $76(0.9)$ & & $56(2.5)$ & $31(1.4)$ & \\
\hline Bronchopulmonary dysplasia & $14(0.5)$ & $17(0.2)$ & & $12(0.5)$ & $1(<0.1)$ & \\
\hline Intraventricular hemorrhage & $25(0.8)$ & $34(0.4)$ & & $20(0.9)$ & $22(1.0)$ & \\
\hline Grade I-II* & $24(0.8)$ & $31(0.3)$ & & $20(0.9)$ & $22(1.0)$ & \\
\hline Grade III-IV & $1(<0.1)$ & $3(<0.1)$ & & 0 & 0 & \\
\hline Periventricular leukomalacia & $2(<0.1)$ & $4(<0.1)$ & & $2(<0.1)$ & 0 & \\
\hline Necrotizing enterocolitis & $12(0.4)$ & $18(0.2)$ & & $10(0.4)$ & $5(0.2)$ & \\
\hline Total neonatal transfers* & $1,636(56.3)$ & $3,561(39.9)$ & & $1,263(55.2)$ & $1,240(54.2)$ & \\
\hline In NICU* & $56(1.9)$ & $104(1.2)$ & & $54(2.4)$ & $36(1.6)$ & \\
\hline Duration in NICU* (d) & $3.4 \pm 2.6$ & $2.2 \pm 1.7$ & & $3.4 \pm 2.6$ & $2.3 \pm 1.7$ & \\
\hline
\end{tabular}

OR, odds ratio; $\mathrm{Cl}$, confidence interval; $\mathrm{NICU}$, neonatal intensive care unit.

Data are $\mathrm{n}(\%)$ or mean \pm standard deviation unless otherwise specified.

* Outcomes were not components of the composite primary outcome. No neonate had phrenic or facial nerve injury.

contributor to the higher composite neonatal mortality and morbidity rate in the planned cesarean delivery group, all other neonatal complications included in the composite primary outcome, except trauma, were also more frequent in this group. Cesarean delivery before labor is strongly associated with respiratory distress in term ${ }^{18,19}$ and late preterm neonates. ${ }^{20}$ The hemodynamic and oxygenation changes associated with cesarean deliveryassociated respiratory morbidity and its potential iatrogenic complications resulting from longer hospitalization might thus explain, at least partly, the higher rates for bronchopulmonary dysplasia, intraventricular hemorrhage, necrotizing enterocolitis, and neonatal sepsis in the planned cesarean delivery group.

Our findings are in accordance with the recent retrospective population-based cohort study of Dong et $\mathrm{al}^{21}$ in which planned cesarean delivery is associated with increased composite adverse perina- tal outcomes between 32 and 35 weeks of gestation in comparison with planned vaginal delivery. However, these data are old (1995-2000) and because of its retrospective design, the intended routes of delivery were speculative, less information was available for the measurement of a discriminating primary outcome, and only few potential confounding factors were taken into account leading to poor adjustments for maternal pathologies. The international randomized trial concluded that planned cesarean delivery between 32 and 39 weeks of gestation neither significantly decreased nor increased the risk of fetal or neonatal death or serious neonatal morbidity compared with planned vaginal delivery. ${ }^{11}$ Nonetheless, twins from the planned cesarean delivery group randomized before 37 weeks of gestation had a trend toward higher perinatal risks. Like that trial $^{11}$ and population-based retrospective cohort studies, ${ }^{7,8,21}$ our results in our low-risk subpopulation suggest planned vaginal, compared with 


\begin{tabular}{|c|c|c|c|c|c|c|}
\hline \multirow[b]{2}{*}{ Outcome } & \multicolumn{3}{|c|}{ Overall Population } & \multicolumn{3}{|c|}{ Low-Risk Population } \\
\hline & $\begin{array}{l}\text { Planned } \\
\text { Cesarean } \\
\text { Delivery } \\
(\mathrm{n}=2,908) \\
\end{array}$ & $\begin{array}{l}\text { Planned } \\
\text { Vaginal } \\
\text { Delivery } \\
(n=8,922)\end{array}$ & OR $(95 \% \mathrm{CI})$ & $\begin{array}{l}\text { Planned } \\
\text { Cesarean } \\
\text { Delivery } \\
(\mathrm{n}=1,128)\end{array}$ & $\begin{array}{l}\text { Planned } \\
\text { Vaginal } \\
\text { Delivery } \\
(n=6,820)\end{array}$ & OR $(95 \% \mathrm{Cl})$ \\
\hline $\begin{array}{c}\text { Composite primary } \\
\text { outcome }\end{array}$ & $150(5.2)$ & $199(2.2)$ & $2.38(1.86-3.05)$ & $28(2.5)$ & $133(2.0)$ & $1.28(0.79-2.08)$ \\
\hline \multicolumn{7}{|l|}{ Death } \\
\hline Antepartum* & $23(0.8)$ & $55(0.6)$ & & 0 & 0 & \\
\hline Perpartum & 0 & 0 & & 0 & 0 & \\
\hline Neonatal & $16(0.6)$ & $11(0.1)$ & & $1(<0.1)$ & $2(<0.1)$ & \\
\hline $\begin{array}{l}\text { Apgar score less than } 4 \text { at } \\
5 \text { min }\end{array}$ & $18(0.6)$ & $25(0.3)$ & & $5(0.4)$ & $16(0.2)$ & \\
\hline Neonatal trauma & $2(<0.1)$ & $16(0.2)$ & & 0 & $9(0.1)$ & \\
\hline Long bone fracture & 0 & $6(<0.1)$ & & 0 & $5(<0.1)$ & \\
\hline Brachial plexus palsy & 0 & $2(<0.1)$ & & 0 & $1(<0.1)$ & \\
\hline Skull fracture & $1(<0.1)$ & $3(<0.1)$ & & 0 & $3(<0.1)$ & \\
\hline Spinal cord injury & $1(<0.1)$ & 0 & & 0 & 0 & \\
\hline Encephalopathy & $7(0.2)$ & $13(0.2)$ & & $1(<0.1)$ & $10(0.2)$ & \\
\hline $\begin{array}{c}2 \text { or more seizures within } \\
72 \mathrm{~h} \text { after birth }\end{array}$ & $1(<0.1)$ & $1(<0.1)$ & & 0 & 0 & \\
\hline $\begin{array}{c}\text { Endotracheal tube greater } \\
\text { than } 24 \mathrm{~h} \text { within } \\
72 \mathrm{~h} \text { after birth }\end{array}$ & $59(2.1)$ & $62(0.7)$ & & $12(1.1)$ & $37(0.6)$ & \\
\hline Proven neonatal sepsis & $55(1.9)$ & $76(0.9)$ & & $9(0.8)$ & $50(0.7)$ & \\
\hline $\begin{array}{c}\text { Bronchopulmonary } \\
\text { dysplasia } \\
\text { Intraventricular } \\
\text { hemorrhage }\end{array}$ & $14(0.5)$ & $17(0.2)$ & & $3(0.3)$ & $10(0.2)$ & \\
\hline Grade I-II* & $24(0.8)$ & $31(0.4)$ & & $2(0.2)$ & $24(0.4)$ & \\
\hline Grade III-IV & $1(<0.1)$ & $3(<0.1)$ & & 0 & $3(<0.1)$ & \\
\hline $\begin{array}{l}\text { Periventricular } \\
\text { leukomalacia }\end{array}$ & $2(<0.1)$ & $4(<0.1)$ & & 0 & $3(<0.1)$ & \\
\hline Necrotizing enterocolitis & $12(0.4)$ & $18(0.2)$ & & $1(<0.1)$ & $10(0.2)$ & \\
\hline
\end{tabular}

OR, odds ratio; $\mathrm{Cl}$, confidence interval.

Data are $\mathrm{n}(\%)$ unless otherwise specified.

* Outcomes were not components of the composite primary outcome. No neonate had phrenic or facial nerve injury.

planned cesarean, delivery after 37 weeks of gestation might be associated with higher composite neonatal mortality and morbidity. However, absolute risks were low, less than $1 \%$, and CIs wide, preventing definitive conclusions. Women should be presented with this information, concomitantly with the short- and long-term maternal risks associated with planned vaginal and cesarean delivery in twin pregnancies, when deciding what the best planned route of delivery is for them.

Like in all observational studies, the main limitation of our study is uncontrolled confounders. We used multiple statistical approaches to reduce bias as much as possible. To control for the indication bias, we performed propensity score analysis and made rigorous adjustments for confounding factors to minimize the likelihood of incorrectly attributing any association to planned cesarean delivery. Although adjustment on the severity of pathologies such as preeclampsia or intrauterine growth restriction was not possible, secondary analyses run after exclusion of high-risk pregnancies, that is, all complicated pregnancies, allowed us to eliminate these potential persisting confounders. Furthermore, secondary analyses in low-risk pregnancies to conform as closely as possible to the Twin Birth Study population ${ }^{11}$ confirmed that delivery before 35 weeks of gestation by planned cesarean was associated with higher composite neonatal mortality and morbidity.

The strengths of the JUMODA study include its population-based cohort design and prospective enrollment of all women giving birth in maternity units performing more than 1,500 deliveries 
annually in France in 2014. The births included in the study account for more than $70 \%$ of all twin births in France each year and more than 95\% of those in maternity units with more than 1,500 annual deliveries. ${ }^{1}$ Attending obstetricians prospectively collected the data about planned mode of delivery and management of delivery so that thorough and accurate information was available for the variable of interest. Furthermore, it provided sufficient statistical power in an unselected population of twin pregnancies to assess the neonatal risks associated with the planned mode of delivery and ensured high external validity of its results. Nonetheless, our findings are only generalizable to large maternity units accustomed to active management of second twin delivery, as recommended in France. ${ }^{16}$

The results of the JUMODA study showed that planned vaginal delivery is associated with low composite neonatal mortality and morbidity in unselected twin pregnancies at or after 32 weeks of gestation with a cephalic first twin. They call for planned vaginal rather than cesarean delivery between 32 and 37 weeks of gestation and strongly support recent American College of Obstetricians and Gynecologists recommendations. ${ }^{12}$

\section{REFERENCES}

1. Blondel B, Kermarrec M, Enquête nationale périnatale 2010. Available at: http://sante.gouv.fr/IMG/pdf/Les_naissances_ en_2010_et_leur_evolution_depuis_2003.pdf. Retrieved April $18,2017$.

2. Hamilton BE, Martin JA, Osterman MJK, Curtin SC, Mathews TJ. Births: final data for 2014. Natl Vital Stat Rep 2015;64:1-64

3. Fishman A, Grubb DK, Kovacs BW. Vaginal delivery of the nonvertex second twin. Am J Obstet Gynecol 1993;168:861-4.

4. Grisaru D, Fuchs S, Kupferminc MJ, Har-Toov J, Niv J, Lessing JB. Outcome of 306 twin deliveries according to first twin presentation and method of delivery. Am J Perinatol 2000; $17: 303-7$.

5. Schmitz T, Carnavalet Cde C, Azria E, Lopez E, Cabrol D, Goffinet F. Neonatal outcomes in twin pregnancy according to the planned mode of delivery. Obstet Gynecol 2008;111: 695-703.

6. Smith GC, Shah I, White IR, Pell JP, Dobbie R. Mode of delivery and the risk of delivery-related perinatal death among twins at term: a retrospective cohort study of 8073 births. BJOG 2005;112:1139-44.

7. Armson BA, O'Connell C, Persad V, Joseph KS, Young DC, Baskett TF. Determinants of perinatal mortality and serious neonatal morbidity in the second twin. Obstet Gynecol 2006; 108:556-64.

8. Smith GC, Fleming KM, White IR. Birth order of twins and risk of perinatal death related to delivery in England, Northern Ireland, and Wales, 1994-2003: retrospective cohort study. BMJ 2007;334:576.

9. Roberts CL, Algert CS, Nippita TA, Bowen JR, Shand AW. Association of prelabor cesarean delivery with reduced mortality in twins born near term. Obstet Gynecol 2015;125:103-10.

10. Lee HC, Gould JB, Boscardin WJ, El-Sayed YY, Blumenfeld YJ. Trends in cesarean delivery for twin births in the United States: 1995-2008. Obstet Gynecol 2011;118:1095-101.

11. Barrett JF, Hannah ME, Hutton EK, Willan AR, Allen AC, Armson BA, et al. A randomized trial of planned cesarean or vaginal delivery for twin pregnancy [published erratum appears in N Engl J Med 2013;369:2364]. N Engl J Med 2013; 369:1295-305.

12. Safe prevention of the primary cesarean delivery. Obstetric Care Consensus No. 1. American College of Obstetricians and Gynecologists. Obstet Gynecol 2014;123:693-711.

13. Schmitz T, Goffinet F. Association of prelabor cesarean delivery with reduced mortality in twins born near term. Obstet Gynecol 2015;125:1247-8.

14. Concato J, Horwitz RI. Beyond randomised versus observational studies. Lancet 2004;363:1660-1.

15. Kotaska A. Inappropriate use of randomised trials to evaluate complex phenomena: case study of vaginal breech delivery. BMJ 2004;329:1039-42.

16. Vayssière C, Benoist G, Blondel B, Deruelle P, Favre R, Gallot $\mathrm{D}$, et al. Twin pregnancies: guidelines for clinical practice from the French College of Gynaecologists and Obstetricians (CNGOF). Eur J Obstet Gynecol Reprod Biol 2011;156:12-7.

17. Lunceford JK, Davidian M. Stratification and weighting via the propensity score in estimation of causal treatment effects: a comparative study. Stat Med 2004;23:2937-60.

18. Hansen AK, Wisborg K, Uldbjerg N, Henriksen TB. Risk of respiratory morbidity in term infants delivered by elective caesarean section: cohort study. BMJ 2008;336:85-7.

19. Jain L, Dudell GG. Respiratory transition in infants delivered by cesarean section. Semin Perinatol 2006;30:296-304.

20. Offermann H, Gebauer C, Pulzer F, Bläser A, Thome U, Knüpfer M. Cesarean section increases the risk of respiratory adaptive disorders in healthy late preterm and two groups of mature newborns. Z Geburtshilfe Neonatol 2015;219:259-65.

21. Dong Y, Luo ZC, Yang ZJ, Chen L, Guo YL, Branch W, et al. Is cesarean delivery preferable in twin pregnancies at $>=36$ weeks gestation? PLoS One 2016;11:e0155692. 